\title{
Improving the Use of Data for HIV Prevention Decision Making: Lessons Learned
}

\author{
Richard A. Jenkins, ${ }^{1,7}$ Abigail R. Averbach, ${ }^{2}$ Ann Robbins, ${ }^{3}$ Kevin Cranston, ${ }^{2}$ \\ Hortensia Amaro, ${ }^{4}$ Allison C. Morrill, ${ }^{4}$ Susan M. Blake, ${ }^{5}$ Jennifer A. Logan, ${ }^{2}$ \\ Kim Batchelor, ${ }^{6}$ Anne C. Freeman, ${ }^{6}$ and James W. Carey ${ }^{1}$
}

\begin{abstract}
HIV prevention community planning was developed to promote identification of local prevention priorities through a process that was evidence-based and provided community input. There are a variety of barriers to effective use of data in community planning which include characteristics of data (availability, timeliness, relevance to planning tasks), characteristics of planning group members and providers of data (e.g., skills in understanding and applying data), and social-organizational aspects of community-planning groups (CPGs). Lessons learned from this project illustrate how to create locally relevant sources of data, build data use skills of CPG members and data providers, and address social-organizational aspects of planning, while also better integrating community planning with implementation of prevention plans. Adaptation of tools and methods is discussed along with future considerations for research and planning practice.
\end{abstract}

KEY WORDS: policy; community planning; data use; technical assistance.

\section{INTRODUCTION}

The papers in this special issue have highlighted barriers to effectively using data for HIV prevention decision making and the value of various tools for overcoming these barriers. Common factors that effect decision making which have been identified through this project include the quality of available data and its relevance to populations of interest (Amaro et al., 2005a; Batchelor

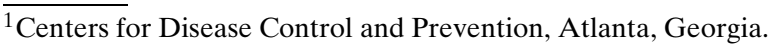

${ }^{2}$ Massachusetts Department of Public Health, Boston, Massachusetts.

${ }^{3}$ Texas Department of Health, Austin, Texas.

${ }^{4}$ Northeastern University, Boston, Massachusetts.

${ }^{5}$ George Washington University, Washington, District of Columbia.

${ }^{6}$ University of Texas Southwestern Medical Center, Dallas,Texas.

${ }^{7}$ Correspondence should be directed to Richard A. Jenkins, PhD, Division of HIV/AIDS Prevention, Centers for Disease Control and Prevention, 1600 Clifton Road, NE, Mailstop E-37, Atlanta, Georgia 30333; e-mail: rgj2@cdc.gov.
}

et al., 2005a), the relevance of data to the planning tasks at hand (Amaro et al., 2005a; Batchelor et al., 2005a), the manner in which data are presented (Amaro et al., 2005a; Batchelor et al., 2005a), and organizational problems that limit the effectiveness of the groups (Amaro et al., 2005a; Batchelor et al., 2005a). Many of the barriers identified here have been observed in past case study evaluations of HIV prevention community planning (e.g., Renaud and Kresse, 1995, 1996; Research Triangle Institute, 1999; Schietinger et al., 1995; United States Conference of Mayors, 1994, 1998) and in other areas of policy-related decision making (e.g., Hammond, 1996; Weiss, 1980). Although these barriers are widely recognized there has been rather little published research or program material describing ways to address these issues.

\section{HIV Prevention Community Planning: Background}

HIV prevention community planning was established as a process whereby state and local 
health departments, funded by the Centers for Disease Control and Prevention (CDC), would share responsibility for developing comprehensive prevention plans with other public agencies, nongovernmental organizations, and representatives of communities affected by or at risk for HIV infection (Valdiserri et al., 1995). The process was meant to increase stakeholder participation and was part of a legislative effort to facilitate identification of prevention priorities at the local rather than federal level. The process also was meant to be evidence-based. Epidemiological data such as AIDS case surveillance form the foundation for this, supplemented by other data sources such as HIV and STD case surveillance, risk behavior surveys, counseling and testing data, program data, and findings from locally conducted research studies, which can vary in scope and quantity across jurisdictions (CDC and HRSA, 2004). The main tasks of community planning groups (CPGs) established under this framework are to prioritize populations, select a set of appropriate interventions, and participate in the development of comprehensive prevention plans, which are the core of each jurisdiction's application for HIV prevention program funds from CDC. The initial guidance for this planning process was developed with input from key stakeholders such as health departments and community representatives (Academy for Educational Development, 1994; CDC, 1993) and was intentionally made flexible and adaptable to varied local conditions. The guidance has been modified in response to feedback and changing conditions (CDC, 1998, 2003a) such as revisions to CDC's HIV Prevention Strategic Plan (2001) and broad programmatic activities such as the recent "Advancing HIV Prevention (AHP) Initiative" (CDC, 2003b).

The resources for effective use of data in HIV prevention community planning differ among jurisdictions. The amount and types of data available for planning purposes vary, and most jurisdictions often lack regular sources of data for addressing important planning and policy areas such as program evaluation (Rugg et al., 2000). CPG membership varies in terms of members' education and technical expertise, as does the availability of technical assistance (TA) and the amount of funding which jurisdictions can provide, apart from their CDC grants. Some geographically large states have multiple, regionally defined CPGs, whose composition and data resources also vary, hence, resources can differ even within a single jurisdiction. Consequently, the efforts needed to address barriers can vary greatly.

\section{TOWARD INCREASING THE USE OF DATA IN HIV PREVENTION COMMUNITY PLANNING}

We developed a logic model (Table I) to help summarize and integrate our findings and experiences from this project. This model includes: major factors that effect decision making and data use in planning groups (previously summarized in Jenkins and Carey, 2005), the specific needs identified in our formative research (Amaro et al., 2005a; Batchelor et al., 2005a), the interventions that emerged from this formative work (Jenkins et al., 2005) and findings from our evaluations (Amaro et al., 2005b; Batchelor et al., 2005b). As is evident here, some barriers were addressed in very different ways by the two participating states, even though Texas and Massachusetts both could be characterized as moderate prevalence jurisdictions (CDC, 2001) and each has considerable geographic variation in HIV prevalence and transmission risks. Much of the difference in approach reflects structural differences between Massachusetts and Texas. Massachusetts, like most states, has a single CPG for the entire state, which allows more intensive attention to group process and the details of data inputs. Texas has multiple, regionally based CPGs with wide variations in the availability of local data and other planning resources. Texas chose a diffusion model (Rogers, 1995) that emphasized TA directed at CPG cochairs, as well as assistance directed toward prevention providers (local public health departments and community-based organizations [CBOs] which provide prevention services to the public), who also participate as CPG members. Texas's efforts also focused primarily on the use of data for selection and adaptation of HIV prevention interventions.

The subsequent sections of the paper will review the components of our logic model in more depth and describe some of the specific tools and methods that have emerged from the project. Lessons learned will be described in terms of broad concepts, more specific implementation issues, and considerations for future research and practice.

\section{Data: Availability, Timeliness, and Relevance}

Past evaluations of community planning have underscored concerns about the relevance and timeliness of available data for community planning (Neal and McNaghten, 1998; Renaud and Kresse, 1996; Research Triangle Institute, 1999; Schietinger et al., 


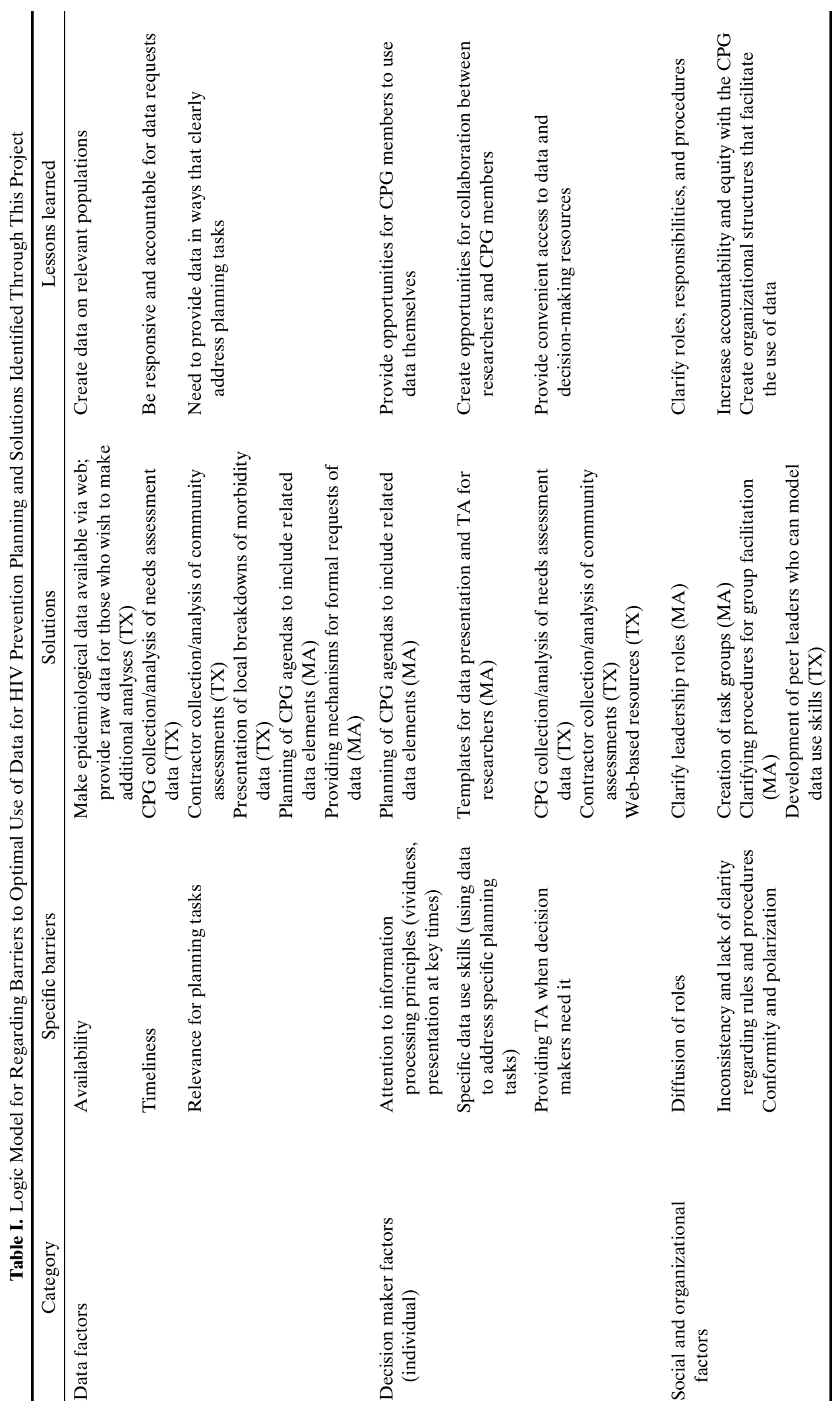


1995; United States Conference of Mayors, 1994, 1998) which affects the planning decisions that can be made (Rugg et al., 2000). The absence of relevant data can create conditions where personal biases and inappropriate shortcuts can easily occur and adversely affect the quality of decision making (Tversky and Kahneman, 1974).

In both Massachusetts and Texas, CPG members general said that the amount of data they received was adequate, but expressed concern about the kinds of data that were available (Amaro et al., 2005a; Batchelor et al., 2005a; Jenkins et al., 2005) and the relevance of those data for the planning tasks they had been given at the time (i.e., prioritization of populations and interventions). In general, CPG members and prevention providers wanted databased findings that were relevant to their localities, their populations of interest, and to the types of interventions that were feasible in their communities. They also noted the lack of data regarding intervention efficacy or cost-effectiveness. In addition, they wanted data to be more clearly related to the planning tasks. The populations they identified as having limited data tended to be ethnic/racial minorities, but within minority populations, a variety of specific subpopulations were identified (MSM, IDU, women, youth). Other common areas of interest included MSM who injected drugs, migrant populations, and recent immigrants. The epidemiological relevance of these populations is easily articulated, yet, data for many of these populations are difficult to acquire on a local basis, particularly with regard to risk behavior. Respondents in the formative work also asked for more timely and relevant data (i.e., data clearly related to local conditions and planning objectives) rather than a greater volume of data. In some cases, the requests could probably be met through further analysis of existing data sources or better presentation of the data (e.g., bringing together different data on populations of interest).

\section{Meeting the Needs for Making More Relevant Data Available}

The needs for increasing the availability and relevance of data were addressed in different ways by Massachusetts and Texas. Massachusetts focused on the way in which data were presented and used in its CPG and also developed mechanisms to facilitate presentation of more relevant kinds of data and data analyses and to ensure that data were interpreted in ways relevant to the CPG's planning tasks. Surveillance staff and outside researchers making data-based presentations now have templates which provide specific formats for displaying surveillance data, surveys, longitudinal trends in data, and so forth along with discussion guides to help presenters make data-based findings more relevant to planning group tasks (e.g., how to consider the implications of data in light of implications, triangulating information from different sources). The templates have not been formally evaluated as of yet, although initial feedback from CPG members has been positive. Massachusetts also reorganized CPG meetings in ways that helped tie together the kinds of data that were routinely presented. For example, data regarding single topics were presented together, so that surveillance data for injection drug users (IDU), program data regarding services for IDU, and outcome data for needle exchange programs all were presented in a single meeting, allowing discussion of these clearly related topics. In addition, Massachusetts set-up "population groups," task groups built around CPG members with shared concerns for specific at-risk populations. These groups review the relevance of presentations in each meeting for their populations. Finally, Massachusetts implemented a data request system, so that specific questions about populations, interventions, etc. could be addressed where data were available, particularly local data. In the past, Massachusetts had resources for funding rapid assessments of specific populations, however, budget cutbacks did not make this possible during the project, although this would represent another mechanism for generating locally relevant data.

Texas, with its multiple regionally based CPGs, faced substantial variation in the type and amount of data that are available for each region. Two different approaches were used to help bridge the gaps in locally relevant data. The Texas CPGs were empowered to collect their own needs assessment data, using a standardized structured instrument with health department TA. In addition, CPG cochairs and prevention providers were provided with training in how to bridge theory and practice and were provided with web-based evaluation materials, including a community assessment manual. Prevention providers who agreed to be part of a training program received more intensive training in these same areas and, subsequently, served as peer leaders in the CBO community. Texas also re-designed its "Epidemic Profile" (the major foundation for constructing 
regional epidemiological profiles, a required part of the prevention plan) to provide more data at a local level, specifically for high and low-morbidity areas within regions. This also was done for counseling and testing data, which were integrated into these profiles. In addition, Texas began to provide raw data for CPG members who preferred to do their own analyses. The "Epidemic Profiles" are now available on the Texas Department of Health website (http://www.tdh.state.tx.us/hivstd/profiles/2000/ default.htm).

\section{Data Users: Training and TA for Decision-Making Tasks}

In both Texas and Massachusetts, it was apparent that additional TA was desired by CPG members (and in Texas's case, prevention providers; Amaro et al., 2005a; Batchelor et al., 2005a; Jenkins et al., 2005). Specifically, there was a desire for more opportunities to interact with researchers, to have more explanation and interpretation of data, and to have more transparency in the selection of data and analyses. The desire for more training and TA in the use of data has been a recurring theme in past evaluations of community planning (United States Conference of Mayors, 1994, 1998) and there has been some effort by academic researchers to develop models of ongoing TA for service providers (Kelly et al., 2000). Typically, new CPG members receive one-shot training that emphasizes "Epi 101" (e.g., "what is a rate?" "what is prevalence?"), whereas the amount and type of ongoing TA tends to be contingent on local resources. Consequently, there are few examples of how to provide TA that is truly integrated into the planning process, although there has been an effort to increase the availability of TA experts, such as through the CDC-funded Behavioral and Social Science Volunteer (BSSV) program run by the American Psychological Association (http://www.apa.org/pi/aids/bssv.html).

\section{Getting CPG Members More Involved With Data}

In this project, TA needs were addressed in a number of different ways. The methods for increasing the use of data in Massachusetts, already described, included more efforts to engage CPG members as data users through "population group" discussions (which occur at each CPG meeting), as well as efforts to better organize the information through thematic sets of presentations and the application of presentation templates and discussion aids. There also has been a purposive effort to restructure the gap analysis process (wherein needs assessment data are reconciled with currently available services). Massachusetts's effort to better solicit data requests also have a TA component; TA staff and members of the Work Plan Committee will work with requesters to shape their requests into researchable questions. Historically, data requests in Massachusetts and elsewhere often have focused on global questions like "what about youth?" In response to questions like these, health departments have not always expended effort to work with requesters to take these concerns and identify ways to see how existing databases can serve them or how researchers in the community may have addressed relevant concerns. The effort to have CPG members and TA providers work together like this provides an opportunity to build trust within the membership and between CPG members and professional staff. Distrust of researchers, and of fellow CPG members, was an issue in the Massachusetts formative work (Amaro et al., 2005a) and has been a concern in past evaluations of community planning (Jenkins and Carey, 2005)

The previously described Texas efforts (facilitating collection of local data by CPGs, training of prevention providers in data use) provided a basis for CPG members to be involved in all stages of data collection and analysis and to receive specific kinds of assistance from the Texas Department of Health or its TA providers. Texas also responded to general concerns about wanting more local data and more data regarding risk behavior, by breaking down morbidity and counseling and testing data by high and low morbidity areas. Texas also provided a questionnaire instrument and TA for conducting local needs assessments. Although many CPG members felt that their novice needs assessment efforts were not very successful, they were motivated to continue doing the needs assessments and improve their efforts. Texas's training of prevention providers to conduct community assessments to help them select and adapt interventions also provided more data to CPGs. The training of providers also meant that there was a cadre of trained peers in the CPGs who could understand how to use data in a variety of ways that have application to the CPGs' tasks. These efforts to address local needs, build local capacity, and promote closer working relationships with TDH and its TA providers also may have created more trust and improved the working alliances in the planning process. Our evaluation 
of the process (Batchelor et al., 2005b) had focused more on operational outcomes of these efforts, however, we also detected greater commitment and enthusiasm about the planning process.

Texas designed a website to make its training tools (tip sheets on interventions, its assessment guide, plus supplementary evaluation resources) available to all CPG members and providers, as well as to interested parties outside of the state, http:// www8.utsouthwestern.edu/utsw/cda/dept156726/files/ 181124.html. The website also serves as "home base" for a web-based discussion group composed of prevention providers. Hence, peer-based TA is further facilitated, along with opportunities to discuss the tools developed in Texas. Discussion in the group is facilitated, in part, by offering a "tip of the month."

\section{TA for Researchers: Helping Data Presentations Better Address Community-Planning Objectives}

Evaluations of community planning have emphasized the need for CPG members to have more and better training in the use of data (e.g., Renaud and Kresse, 1995, 1996; Research Triangle Institute, 1999; United States Conference of Mayors, 1994, 1998). The findings here underscore a parallel need for researchers involved in the planning process to better understand the use of data, as well. This need previously has been identified in the policy planning and evaluation literatures (e.g., Innes, 1990; Patton, 1997; Weiss, 1980, 1998). The Massachusetts effort to develop templates and presentation guides for researchers provided a basis for directing TA toward researchers who present to their CPG. These will be accompanied by more specific suggestions and feedback for presentations from one of Massachusetts's TA providers. CDC has recognized some of this need in its recent revision of guidance for constructing epidemiological profiles (jointly issued with the Health Resources and Services Administration [HRSA] to also address HRSA-funded HIV care planning) which includes of templates for developing epidemiological profiles for CPGs and Ryan White planning processes (CDC and HRSA, 2004). The CDC/HRSA document also provides detailed information about data sources and their availability by jurisdiction and provides examples for integrating some of these data, although CPG members may still need TA for considering the best use of these data (where available) for their specific planning needs.

\section{Using Peer Groups to Improve Data Use}

In Texas, the varied distribution of TA resources across different regions has been partly remedied by the presence of CPG members who had participated in Texas's training of prevention providers in data-based areas related to intervention selection (described previously). The advantage of this kind of peer leadership is that it capitalizes on the tendency for service providers to consult among their peers in seeking information regarding the selection of interventions (Collins and Franks, 1996), and is consistent with Texas's own findings that peers were the most valued sources of information (Batchelor et al., 2005a). Texas also has made parallel efforts to make similar information available to CPG members, particularly cochairs, who participate in annual state-wide meetings. These trainings have accompanied the increased availability of morbidity and risk behavior data, described previously. These trainings appear to have had less impact on CPGs than the training of providers (Batchelor et al., 2005b).

\section{Social-Organizational Factors in Using Data}

At the outset, this project focused on data use and, while we recognized the impact of group dynamics on the deliberations of CPGs, we did not fully appreciate the social and organizational aspects of using data. In Massachusetts, the presence of a single CPG permitted intensive assessment of group process and interventions to address the social-organizational functioning of the group, which has been a precondition for addressing more purely technical data-based needs of the group (e.g., presentation templates). Findings from Massachusetts's formative data underscored this strategy as integral to data use (Amaro et al., 2005a).

Interestingly, CPG members in both states viewed themselves as making more data-based decisions than their colleagues in the groups, who were seen as relying more on anecdotes and clinical experience. This would seem to be an example of the classic "actor-observer" discrepancy in attributing motives (Heider, 1958), wherein one's own behavior may be seen as being influenced by factors different than those which influence others. TA efforts need to address this by focusing on the many considerations that go into a decision and the ways in which people can focus on the data. 
Group process can lead in many different directions. Group membership can lead to polarization as well as conformity (Plous, 1993). It also can lead to the adoption of new ideas or actions that individual group members would not necessarily adopt on their own (Plous, 1993). Groups need to facilitate creativity and participation by their full membership, while also guarding against conditions that foster conformity, bias, and suspicion. The need for inclusion and diverse opinion often gets confused with exercising a loose approach to facilitation of a group, which can lead to diffuse goals and expectations within the group, as well as inequity in the distribution of power (Cherniss and Deegan, 2000; Kreuter et al., 2000). Rules and bylaws are needed in order to insure inclusion and proper deliberation about data and CPGs need to be organized to carry out their tasks and decide how to delegate work within the group, as well as delegate some tasks to outside TA providers (Dearing et al., 1998). A coherent organization (one where there is clarity regarding tasks and procedures, and distribution of responsibility) is essential to group members' being able to use data and for research staff to adequately understand program and planning concerns in a group (Weiss, 1998).

\section{Changing the Rules: Creating More Clarity and Participation}

In the case of Massachusetts, many members were concerned that the rules that governed proceedings had become muddled, that areas of responsibility within the group were blurred and, that conflicts of interest were present in the leadership (Amaro et al., 2005a). These kinds of conditions have been identified in many kinds of citizens' groups and provider coalitions (Cherniss and Deegan, 2000; Kreuter et al., 2000) and called for efforts to provide structures which help provide greater equity and clearer roles and responsibilities in the group. The interventions undertaken by Massachusetts restructured responsibilities and established more formal procedures for the conduct of meetings, while also creating structures (the "population groups") that created new opportunities for discussion and deliberation. The changed committee structure distributed responsibilities that had been centralized in the CPG's steering committee, a body that was seen as being too closely aligned with the health department (Amaro et al., 2005a; Jenkins et al., 2005). Hence, more members could be part of governance and no single body controlled the structure and process of the CPG's meetings. After implementation of these changes, there was a significant increase in satisfaction regarding the decision-making process and, in particular, greater satisfaction with activities related to intervention prioritization (Amaro et al., 2005b).

\section{THE BIGGER PICTURE: WHAT DO COMMUNITY-PLANNING GROUPS NEED?}

\section{More Relevant Data, Not Just More Data}

Respondents in our formative work sought more data, yet felt overwhelmed with the existing data, regardless of its range or quantity (Amaro et al., 2005a; Batchelor et al., 2005a; Jenkins et al., 2005). Much of the additional data people wanted to see could be characterized as being "more relevant" data, in terms of being more reflective of local communities or of particular populations believed to be atrisk. Where resources are available, CPGs can commission rapid assessments or other supplementary data, although budgetary constraints may limit this in many jurisdictions. Another approach is for the CPG to collect its own data with TA from the health department or its TA providers, as was done in Texas (which enabled CPGs to satisfy the needs assessment requirement for their prevention plans). Prevention providers also were engaged in data collection tasks in Texas and performed qualitative community assessments (Batchelor et al., 2005b). The CDC staff from this project have worked with other jurisdictions to undertake these kinds of activities. This process not only provides a way to generate locally relevant data for important populations, but it also provides hands-on experience that permits nonresearchers to better understand how to frame research questions and how data can or cannot address policy questions.

Increased relevance also can come from existing data, through additional analysis and through better integration of data. Texas developed logic models to help guide the use of behavioral data to facilitate selection of interventions. Massachusetts' TA for data providers and their CPG includes help with triangulating data from different sources as they relate to specific populations or interventions. Massachusetts' revised procedures for intervention prioritization will include logic models to help identify data sources and implications from these data for choosing among specific interventions. 
Training and TA Needs: Specific Skills, Not Just Epi 101

A recurrent finding in past evaluations of community planning has been the desire for more training. In particular, CPG members have wanted training apart from the didactic introductions to planning and epidemiological concepts that typically serve as members' orientation to the planning process (e.g., Renaud and Kresse, 1995, 1996; Research Triangle Institute, 1999; United States Conference of Mayors, 1994, 1998). In practice, there have been few tools to provide ongoing TA and local resources often pose realistic constraints to ongoing TA and training efforts. In this project, there have been several ways to infuse ongoing TA into the planning process. These have included having CPG members become involved with health departments in collecting and analyzing needs assessment data with appropriate TA, training cochairs in the use of data for selecting interventions, and training prevention providers to collect community assessment data and apply it to intervention selection and adaptation. Having cochairs and CPG members (i.e., the prevention providers who also sit on CPGs) who have training and hands on experience with data, it is possible to supplement professional TA to CPGs with knowledgeable people who can act as peer leaders (Batchelor et al., 2005b; Jenkins et al., 2005). CPGs are not expected to collect and analyze their own data, although this sometimes occurs in practice, typically with supervision from health departments or their TA providers. Efforts to make presentations more accessible and relevant to the planning process represent yet another channel for providing TA (Amaro et al., 2005b; Jenkins et al., 2005). Outside of the CPG meetings, the availability of web-based materials is another way to make tools readily available (Batchelor et al., 2005b; Jenkins et al., 2005).

\section{TA is for Researchers Too}

The need for researchers to understand uses of the data has been well-documented in the evaluation literature (Patton, 1997; Weiss, 1980, 1998), but has received less attention in the HIV prevention planning literature. The efforts to develop presentation templates and standard questions for researchers, and the provision of TA to help presentations fit CPG needs (undertaken by Massachusetts) represent ways in which researchers can be helped to make their presentations to CPGs more valuable to planning groups and, more importantly, more likely to be used (Amaro et al., 2005b; Jenkins et al., 2005). The efforts by Texas to have CPGs collect needs assessment data created opportunities for researcher members of CPGs to better understand the nonresearcher perspective in conducting these assessments (Batchelor et al., 2005b; Jenkins et al., 2005).

Beyond providing TA for specific technical deficits among researchers, there need to be ways for data-driven planning to be more collaborative, a process which may decrease the distrust between CPG members and those who provide data. Moreover, this is likely to further the technical competencies of researchers and CPG members in being able to apply to data to planning tasks. Work with comprehensive community initiatives (e.g., Milligan et al., 1999) and with substance abuse coalitions (Fetterman et al., 1996) has illustrated the importance of collaborations between researchers and community members in defining issues, as well as in collecting and analyzing data. Efforts to have CPGs and prevention providers collect and analyze data (undertaken in Texas, with TA provided by TDH's TA provider) provide steps in this direction. In Texas, this was part of a logic model-driven approach to planning and followed the training of CPG members in methods for using data and theory to define problems (e.g., identifying factors that influence risk behavior) and guide their selection of interventions (Batchelor et al., 2005b; Jenkins et al., 2005). Massachusetts is going in a similar direction with development of intervention prioritization tools that use logic models that are based on available sources of data. Massachusetts's effort to formalize requests for data represents another approach in making the process more collaborative and in helping CPG members better frame research questions, while forcing researchers to grapple with how to explain what research data can or cannot address and how to constructively consider the limitations of data (Amaro et al., 2005b; Jenkins et al., 2005).

\section{Decision Making is a Social Process}

Decision making in a group requires that there be leadership, division of tasks, and procedures for moving work through committees and resolving disagreements (Backer, 2003; Cherniss and Deegan, 2000; Dearing et al., 1998; Kreuter et al., 2000). Often, a rather freeform approach to group process has been taken in CPGs and other community 
planning-type efforts, with the assumption that this made the group more egalitarian. Ironically, the absence of assertive leadership and clear procedures to insure orderly proceedings often lead to inequity and the kinds of conflict, polarization, or conformity that undermine the value of a group (Cherniss and Deegan, 2000; Plous, 1993; Roussos and Fawcett, 2000). Setting up these structures and determining the scope of work to be taken on by the groups (as opposed to work that CPGs delegate to health departments or research contractors) is time consuming, even when the social climate of the CPG is agreeable (Dearing et al., 1998). Dealing with these issues in an existing group is also likely to be time consuming. Still, a well-functioning group should be seen as a precondition before TA can address the technical specifics of data use. Much of the initial work in Massachusetts was focused on better determining roles and responsibilities within the group, with the establishment of task groups and clearer procedures for the facilitation of meetings and CPG business (Amaro et al., 2005b; Jenkins et al., 2005). In Texas, the presence of multiple CPGs with differing needs and resources made this kind of intensive work more difficult, however, the effort to use a diffusion model (Rogers, 1995) and develop increased capacity with cochairs and prevention providers (who were also involved in their regional CPGs) made a substantial difference in the content and process of CPG meetings (Batchelor et al., 2005b). Hence, having people who can lend expertise and have the respect of their peers may be an approach to use where TA resources are more limited and/or multiple groups exist in a jurisdiction.

\section{The Need for Legacy}

Other community planning-type efforts have failed to leave well-documented legacies or tools to facilitate the planning process. Much of what we know from past efforts like Great Society programs (Gans, 1973; Innes, 1990; Moynihan, 1969; Weiss, 1998) and community mental health initiatives (Heller et al., 2000) is what went wrong. The literature on effective operation of task groups for policy and planning is limited and often fails to get incorporated into the "stove piped" literatures that grow up around the different areas of categorical funding for health services (e.g., HIV, substance abuse, child health) or other areas of planning (e.g., land use, social services). In addition, much of the research literature on group behavior is based on laboratory experiments rather than on observation of on-going task groups. Even so, experience with community initiatives (Cherniss and Deegan, 2000) and community coalitions (Backer, 2003; Butterfoss et al., 1996; Roussos and Fawcett, 2000) outside of HIV community prevention planning offer important lessons, which have already been noted here (e.g., importance of well-defined policies and procedures to promote equity and promote fair and accountable leadership). This thematic issue of AIDS and Behavior is an attempt at providing some legacy materials that can be used for other kinds of planning in HIV (e.g., Ryan White Councils) and in other kinds of community-based planning and policy initiatives, such as comprehensive community initiatives (e.g., Milligan et al., 1999). The websites set-up by Texas (http://www8.utsouthwest ern.edu/utsw/cda/dept156726/files/181124.html) and Massachusetts (http://www.mass.gov/dph/aids/toolkits /toolkits.htm) provide specific materials that are integral to this legacy, as well as being practical for ongoing HIV prevention planning.

\section{Consideration of Context}

In this project, we had two jurisdictions approach similar problems in very different ways. These illustrate how one may conceptualize needs as a function of local planning resources and organization. Where there is a single CPG, the approach taken by Massachusetts may be more feasible, because a single CPG allows more intensive scrutiny of process, procedures, and individual data inputs. Where there are multiple CPGs, one needs to look for approaches that can spread resources over more people, such as the diffusion models of TA and webbased tools that were developed in Texas. Another approach is to look for ways to address multiple planning tasks and TA needs. The focus on prevention providers in Texas provided this as it increased the capacity of agencies to carry out prevention plans (with evidence-based interventions) while also developing a cadre of people who could provide peer leadership, as well as formal and informal TA within the CPGs.

There also are ways to blend the tools used here. The presentation templates may be useful, even where there are multiple CPGs because they help standardize the type and quality of presentations. Local TA may vary in being able to adapt the presentation guides that accompany the templates, however, these materials may be a useful starting place for many jurisdictions. The need to restructure 
CPGs occurs on a periodic basis and the structure adopted by Massachusetts may represent a useful model for CPGs to consider among their alternatives. Similarly, the Texas web site provides materials that can be used by other CPGs (e.g., fact sheets; community assessment manual) in hard copy or web-based form. The content of the website also can be used to reinforce CPG efforts such as efforts to communally conduct community assessments or seek out materials for identifying effective interventions for prevention plans.

\section{Adaptation of Our Tools and Techniques}

Many, if not most, of the tools developed in this project can be adapted to other jurisdictions. When they have been presented to health department staff, CPG members, and CDC staff, there has been great enthusiasm. In some cases, little, if any change is necessary and we have purposely made materials for other jurisdictiosn, so that local resource limitations in other places can be mitigated. For example the Texas TA website, http://www8.utsouthwestern.edu/utsw/cda/dept156726/ files/181124.html, could easily be provided to prevention providers or CPG members, and linked to health department or TA sites for other jurisdictions. Most of the materials are not Texas-specific and it would be easy for CPGs and CBOs elsewhere to use them. Much the same could be said for the Massachusetts website, http://www.mass.gov/dph/aids/toolkits/toolkits.htm . Much of the Texas-developed training content is available as part of the normal offerings of the STD/HIV Prevention Behavioral Intervention Training Center operated by University of Texas-Southwestern. Similar courses may be offered in the other Behavioral Training Centers, funded by CDC. The most important considerations are whether the tools fit the local situation, how they will be used and who will use them. The incentive for using evidence-based interventions in prevention plans or in practice is greater if they are part of the request for applications that goes out to prevention providers. This was an important part of the Texas strategy.

Jurisdictions may find additional resources useful, in addition to those developed for this project. There are a number of web-based evaluation sites which can be used to supplement the Texas site, such as the American Psychological Association's (APA) program evaluation webpage, which was designed by their office on AIDS to help behavioral and social scientists provide evaluation TA to CBOs and CPGs (http://www.apa.org/pi/aids/introprogrameval.html). Research on the evaluation of social and operational dimensions of planning groups has begun to appear in the research literature and there are now useful, practical measures that could supplement those used here (see, e.g., Wolff, 2003). Community collaborations that build data warehouses for planning, policy, and community empowerment purposes, are increasingly prevalent and represent potential sources of supplemental data. These collaborations typically include academic, nonprofit, and public partners (sometimes including local health departments) and may provide additional sources of data analysis TA, as well as raw data inputs. The National Neighborhood Indicators Project (http://www.urban.org/nnip/about.html), a national network of collaborations in medium to large metropolitan areas (described in Howell et al., 2003 ) is one of a number of relevant collaborations of this type. This kind of network may be considered by health departments or CPGs as a way of further strengthening their TA efforts and case examples from this network's activities are provided by Milligan et al. (1999).

Many CPGs do not have the resources to conduct the kind of evaluation that was done in this project. However, adoption of tools should follow from some evaluation of current needs and an evaluation of how well tools meet current needs. Existing, ongoing process evaluation tools in CPGs could be adapted to include some of the topics that were addressed in our formative (Amaro et al., 2005a; Batchelor et al., 2005a) or outcome evaluations (Amaro et al., 2005a; Batchelor et al., 2005b). Process evaluations also might incorporate some of the self-evaluation tools developed by Massachusetts. Although detailed observations of CPGs such as those done in Massachusetts may be impractical where resources are limited, the topics addressed in these observations may be feasibly addressed through less labor intensive forms of observation, such as checklists or summary observations made by process evaluators.

\section{Incentivizing Data Use}

One way to increase data use is to provide concrete incentives for this to occur, a strategy that is often neglected (Weiss, 1980). Both Texas and 
Massachusetts became more explicit in their expectations regarding the need for funded prevention services to be evidence-based. This kind of approach makes it easier to determine whether the funded services match the evidence-based intervention profiles required in the prevention plan. Creating this expectation means that a CPG's prevention plan that clearly uses data to select interventions and gives attention to interventions with demonstrated efficacy will actually be implemented by the funding jurisdiction. Similarly, this same set of expectations will encourage prevention providers to pay more attention to evidence-based interventions and that will have spill over effects in the way they participate in CPGs. Increasing the incentives for using data may also "raise the bar" in terms of TA needs; hence, it is important to be able to provide appropriate training, and access to detailed information regarding interventions with demonstrated effectiveness. Indeed, Texas found that simply changing the funding requirements was insufficient to change data use alone. The CPGs most able to address Texas's requirements were those where cochairs and/or prevention contractor-members had training and experience from this project (Batchelor et al., 2005b).

\section{Limitations of the Tools and This Project}

There are a number of practical and empirical limitations to the tools and findings from this project. The nature of community planning means that CPGs involve relatively small numbers of people in groups whose membership typically turns over within a 2-3-year period. Consequently, studies in a single jurisdiction are bound by sample size limitations and changes in cohort membership which can affect longitudinal findings. Further, exogenous factors like funding and policy (see next section) can exert substantial influence over the operation of planning groups, the social climate of these groups and the attitudes of individual group members. Finally, even where multiple CPGs are present (e.g., Texas), the differences in resources, geography, etc. may not make it possible to use different CPGs as comparison groups, which was a consideration here. It also was not feasible to experimentally assign prevention providers in Texas to different interventions, so, instead, there was an effort to have all community planning regions represented. Despite these limitations, the barriers to data use examined here have been widely observed elsewhere although those observations have not led to welldeveloped methods for mitigating these barriers. Hence, the tools developed here and the case study evidence for their value represent a substantial advance in this area. Another consideration is that we attempted to include measures that were relatively nonreactive, such as meeting observations and archival review of planning documents, whereas the other research in this area has relied almost entirely on surveys or qualitative interviews, alone.

\section{FUTURE DIRECTIONS FOR RESEARCH}

One of the things that we found most striking in the development of this project was the lack of relevant research. The past efforts to look at HIV prevention community planning have used surveys and qualitative case studies, as we did. However, there had been relatively little attention to group process and little effort to develop and evaluate new tools for planning. CPGs and other kinds of policy and planning task groups have tremendous potential for researchers, which is beginning to be recognized (e.g., Kreuter et al., 2000; Roussos and Fawcett, 2000). They provide a venue for looking at group decision processes outside of typical laboratory settings and research efforts could provide away for decision-making researchers to help apply the vast literature on decision making to improve the planning process (a brief summary of the decision-making literature is provided in Jenkins and Carey, 2005). This could benefit CPGs in terms of more effective group process and further development of training and TA materials that utilize current knowledge in cognitive science. Because CPGs typically have a process evaluation component and often have participation by researchers in the community and access to research TA through programs like the BSSV program described previously, there is some infrastructure on which to build research efforts. The need for decision-making research and the world of policy and planning practice to talk with each other has often been recognized (e.g., Hammond, 1996; Innes, 1990; Weiss, 1980) but with minimal follow-through. Efforts to build on existing infrastructure and to increase the process evaluation expectations of HIV prevention community planning would be important steps to remedy this situation. 


\section{Factors That Occur Outside of the Planning Process}

Weiss (1998) has noted that the use of data for decision making can be greatly affected by factors outside of the planning process. Changes in funding and policy can override data considerations, as can changes in the general social, political, or economic climate. During the course of this project, Texas and Massachusetts experienced substantial reductions in their state budgets for HIV prevention which had impacts on planning. For example, Massachusetts had to reduce the frequency of its CPG meetings (from monthly to every other month). Changes such as reduced frequency of meetings or diminished resources for subcommittee meetings, travel, contracted research, or TA have occurred in many jurisdictions because of this and changes like these jeopardize efforts to improve HIV prevention community planning. Texas and Massachusetts have been able to construct tools in this project that can be sustained after the close of funding, including materials and websites and their continued availability will help these jurisdictions, as well as others who wish to use these tools.

A significant policy change that will effect community planning in the future is the CDC's "Advancing HIV Prevention (AHP) Initiative" (2003b) which gives increased emphasis to prevention for HIV seropositives and calls for the greater implementation of HIV testing in primary care and nonclinic settings, as well as more attention to seronegative partners of HIV-seropositive persons and to antenatal transmission. In many jurisdictions, including Texas and Massachusetts, HIV-seropositives had already begun to gain recognition as an important population for prevention planning. Similarly, HIV counseling and testing, including services outside of clinic settings, have been a long-time component of most prevention programs. In many jurisdictions, the changes in behavioral surveillance that accompany this initiative will increase the amount of behavioral data available for high morbidity populations which should increase the amount of information that is available and relevant, particularly for intervention selection, as well as for population prioritization. Nonetheless, this initiative will raise questions for CPGs about their roles in the planning process and will require them to better clarify the areas where they have the most influence over the planning process. This will mean that attention to the social/organizational process of planning and relations between CPGs and health departments will grow more important and that CPGs may want to refashion the role they have previously been given.

\section{ACKNOWLEDGMENTS}

The authors acknowledge the helpful comments made by Bob Kohmescher, Ann O'Leary, Ron Stall, and two anonymous reviewers on earlier drafts of the manuscript. Important formative ideas for this project were provided by Lynda Doll. Some of the material in this paper was previously been presented at the 2002 and 2003 Community Planning Leadership Councils (in Atlanta and New York, respectively) and at the 2003 US Conference on AIDS in Atlanta, GA. This project was funded under CDC program announcement \#99098.

\section{REFERENCES}

Academy for Educational Development (1994). Handbook for $H I V$ prevention community planning. Washington, DC: Academy for Educational Development.

Amaro, H., Conron, K. J., Mitchell, E. M. H., Morrill, A. C., Blake, S. M., and Cranston, K. (2005a). HIV prevention community planning: Challenges and opportunities for datainformed decision-making. AIDS and Behavior, 9(2), S9-S27.

Amaro, H., Morrill, A. C., Dai, J., Dunn, S., Blake, S. M., and Cranston, K. (2005b). HIV prevention community planning: Enhancing data-informed decision making. AIDS and Behavior, 9(2), S55-S70.

Backer, T. E. (2003). Evaluating community collaborations: An overview. In T. E. Backer (Ed.). Evaluating community collaborations (pp. 1-18). New York: Springer.

Batchelor, K., Freeman, A. C., Robbins, A., Dudley, T., and Phillips, N. (2005a). A formative assessment of the use of behavioral data in HIV prevention inTexas. AIDS and Behavior, 9(2), S29-S40.

Batchelor, K., Robbins, A., Freeman, A. C., Dudley, T., and Phillips, N. (2005b). After the innovation: Outcomes from the Texas behavioral data project. AIDS and Behavior, 9(2), S71S86.

Butterfoss, F. D., Goodman, R. M., and Wandersman, A. (1996). Community coalitions for prevention and health promotion: Factors predicting satisfaction, participation, and planning. Health Education Quarterly, 23, 65-79.

Centers for Disease Control and Prevention [CDC] (1993). Guidance, HIV prevention community planning for HIV prevention cooperative agreement recipients. Atlanta, GA: Centers for Disease Control and Prevention.

Centers for Disease Control and Prevention [CDC] (1998). HIV prevention community planning for HIV prevention cooperative agreement recipients. Atlanta, GA: Centers for Disease Control and Prevention.

Centers for Disease Control and Prevention [CDC] (2001). Summary of notifiable diseases, 1999. Morbidity and Mortality Weekly Report, 48, 1-124.

Centers for Disease Control and Prevention [CDC] (2003a). HIV prevention community planning guide. Atlanta, GA: Centers for Disease Control and Prevention. 
Centers for Disease Control and Prevention [CDC] (2003b). Advancing HIV prevention: New strategies for a changing epidemic-United States, 2003. Morbidity and Mortality Weekly Report, 52, 329-332.

Centers for Disease Control and Prevention [CDC] and Health Services Research Administration [HRSA] (2004). Integrated guidelines for developing epidemiologic profiles: HIV prevention and Ryan White CARE Act community planning. Atlanta, GA and Rockville, MD: Centers for Disease Control and Prevention and Health Services Research Administration.

Cherniss, C., and Deegan, G. (2000). The creation of alternative settings. In J. Rappaport and E. Seidman (eds.), Handbook of community psychology (pp. 359-377). New York: Kluwer Academic.

Collins, C., and Franks, P. (1996). Improving the use of behavioral research in CDC's HIV prevention community planning process. Monograph series, Occasional paper \#1, San Francisco: Center for AIDS Prevention Studies.

Dearing, J. W., Larson, R. S., Randall, L. M., and Pope, R. S. (1998). Local reinvention of the CDC HIV prevention community planning initiative. Journal of Community Health, 23, 113-126.

Fetterman, D. M., Kaftarian, S., and Wandersman, A. (1996). Empowerment evaluation: Knowledge and tools for selfassessment and accountability. Thousand Oaks, CA: Sage.

Gans, H. J. (1973). More equality. New York: Parthenon.

Hammond, K. R. (1996). Human judgment and social policy. New York: Oxford.

Heider, F. (1958). The psychology of interpersonal relations. New York: Wiley.

Heller, K., Jenkins, R. A., Steffen, A., and Swindle, R. W. (2000). Prospects for a viable community mental health system: Reconciling ideology, professional traditions, and political reality. In J. Rappaport and E. Seidman (eds.), Handbook of community psychology (pp. 445-470), New York: Kluwer Academic.

Howell, K., Pettit, L. S., Ormond, B. A., and Kingsley, G. T. (2003). Using the national neighborhood indicators partnership to improve public health. Journal of Public Health Management and Practice, 9, 235-242.

Innes, J. E. (1990). Knowledge and public policy: The search for meaningful indicators (2nd ed.). New Brunswick, NJ: Transaction.

Jenkins, R. A., and Carey, J. W. (2005). Special issue: Introduction and background. AIDS and Behavior, 9(2), S1-S8.

Jenkins, R. A., Robbins, A., Cranston, K., Batchelor, K., Freeman, A. C., Amaro, H., Morrill, A. C., Blake, S. M., Logan, J. A., and Carey, J. W. (2005). Bridging data and decision making: Development of techniques for improving the HIV prevention community planning process. AIDS and Behavior, 9(2), S41-S53.

Kelly, J. A., Somlai, A. M., DiFrancisco, W. J., Otto-Salaj, L. L., McAuliffe, T. L., Hackl, K. L., Heckman, T. G., Holtgrave, D. R., and Rompa, D. (2000). Bridging the gap between the science and service of HIV prevention: Transferring effective research-based HIV prevention interventions to community AIDS service providers. American Journal of Public Health, 90, 1082-1088.

Kreuter, M. W., Lezin, N. A., and Young, L. A. (2000). Evaluating community-based collaboration mechanisms: Implications for practitioners. Health Promotion Practice, 1, $49-63$.
Milligan, S., Coulton, C., York, P., and Register, R. (1999). Implementing a theory of change evaluation in the Cleveland Community-Building Initiative: A case study. In K. Fulbright-Anderson, A. C. Kubisch, and J. P. Connell (eds.), New approaches to evaluating community initiatives, Volume 2: Theory, measurement, and analysis (pp. 45-85). Washington, DC: Aspen Institute.

Moynihan, D. P. (1969) Maximum feasible misunderstanding. New York: Free Press.

Neal, J. J., and McNaghten, A. D. (1998, July). Trends in the use of epidemiological data in HIV prevention community planning in the United States, 1994 through 1997. Paper presentation at the XII International Conference on AIDS, Geneva.

Patton, M. Q. (1997). Utilization-focused evaluation: The new century text. Newbury Park, CA: Sage.

Plous, S. (1993). The psychology of judgment and decision making. New York: McGraw-Hill.

Renaud, M., and Kresse, E. (1995). HIV prevention community planning profiles: Assessing year one. Washington, DC: United States Conference of Mayors.

Renaud, M., and Kresse, E. (1996). HIV prevention community planning profiles: Assessing the impact. Washington, DC: United States Conference of Mayors.

Research Triangle Institute (1999). Final report: An assessment to determine program evaluation technical assistance needs, wants, resources, services, service gaps, and preferred methods of responding to technical assistance requests of health departments, community planning groups, community-based organizations, and CDC staff in the context of HIV prevention. $\mathrm{Re}-$ search Triangle, NC: Research Triangle Institute. (Prepared for CDC-DHAP, Program Evaluation Research Branch.)

Rogers, E. M. (1995). Diffusion of innovations (4th ed). New York: Free Press.

Roussos, S. T., and Fawcett, S. B. (2000). A review of collaborative partnerships as a strategy for improving community health. Annual Review of Public Health, 21, 369-402.

Rugg, D. L., Heitgerd, J. L., Cotton, D. A., Broyles, S., Freeman, A., Lopez-Gomez, A. M., Cotten-Oldenburg, N. U., and Page-Shafer, K. (2000). CDC HIV prevention indicators: Monitoring and evaluating HIV prevention in the USA, AIDS, 14, 2003-2013.

Schietinger, H., Coburn, J., and Levi, J. (1995). Community planning for HIV prevention: Findings from the first year. AIDS and Public Policy Journal, 10, 140-147.

Tversky, A., and Kahneman, D. (1974). Judgment under uncertainty: Heuristics and biases. Science, 185, 1124-1131.

United States Conference of Mayors (1994). HIV prevention community profiles: Assessing year one. Washington, DC: United States Conference of Mayors.

United States Conference of Mayors (1998). HIV prevention community profiles: Assessing the process and the evolving effects. Washington, DC: United States Conference of Mayors.

Valdiserri, R. O., Aultman, T. V., and Curran, J. W. (1995). A national strategy to improve HIV prevention programs. Journal of Community Health, 20, 87-100.

Weiss, C. H. (1980). Social science research and decision-making. New York: Columbia University Press.

Weiss, C. H. (1998). Have we learned anything new about the use of evaluation? American Journal of Evaluation, 19, 21-33.

Wolff, T. (2003). A practical approach to evaluation of collaborations. In T. E. Backer (Ed.). Evaluating community collaborations (pp. 57-112). New York: Springer. 